\title{
Calcified bullet thrombus of the inferior vena cava
}

\author{
Edward Y. Lee $\cdot$ Roy McCauley
}

Received: 12 February 2010 /Revised: 23 April 2010 /Accepted: 14 May 2010 / Published online: 11 June 2010

(C) Springer-Verlag 2010

A 12-year-old girl underwent plain radiographs of the spine for evaluation of underlying scoliosis. A triangular, bullet-shaped opacity (arrow) was observed in the right paravertebral location at the L1 level (Fig. 1). Also noted are underlying levoscoliosis of lumbar spine and metallic devices from a body brace. Subsequent US shows calcified thrombus (arrow) in the inferior vena cava (IVC) consistent with calcified bullet thrombus of the IVC (Fig. 2).

A "bullet" thrombus is a calcified triangular-shaped thrombus of the IVC of unknown etiology first described by Singleton but it was Silverman who first used the adjective, "bullet" shaped $[1,2]$. In addition to an isolated

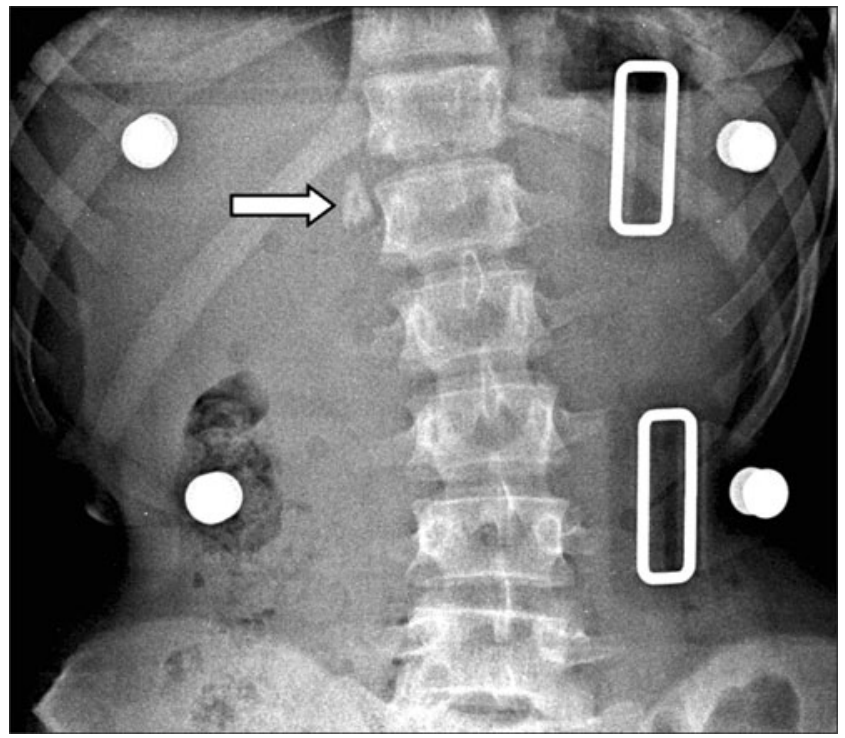

Fig. 1 Plain radiograph of lumbar spine

E. Y. Lee $(\bowtie) \cdot R$. McCauley

Department of Radiology, Children's Hospital Boston and Harvard Medical School,

300 Longwood Ave.,

Boston, MA 02115, USA

e-mail: Edward.Lee@childrens.harvard.edu

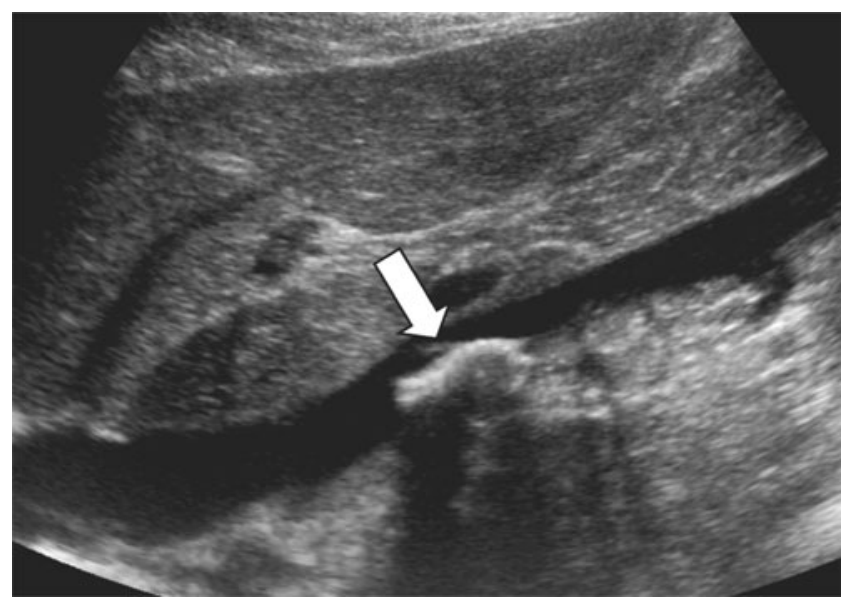

Fig. 2 Sagittal US view of the inferior vena cava

thrombus in the IVC, we have seen a case in which there was a bullet thrombus associated with left renal vein thrombosis. On plain radiograph, the right paravertebral bullet-shaped calcification is diagnostic and usually no further investigation is necessary $[1,2]$. However, if the thrombus is not completely calcified in the neonatal period, other possibilities including adrenal hemorrhage and neuroblastoma should be considered [2]. Definitive diagnosis can usually be made by US, as in our case. The thrombus characteristically lies in the upper IVC and does not obstruct flow. So far, no deaths or complications from a calcified bullet thrombus have been reported and no specific treatment appears to be necessary $[1,2]$.

\section{References}

1. Silverman NR, Borns PF, Goldstein AH et al (1969) Thrombus calcification in the inferior vena cava. Am J Roentgenol Radium Ther Nucl Med 106:97-102

2. Schullinger JN, Santulli TV, Berdon WE et al (1978) Calcific thrombi of the inferior vena cava in infants and children. J Pediatr Surg 13:429-434 